\title{
A GENERALIZED CORRELATION FOR CONDENSATION ON VERTICAL FLUTED SURFACES
}

\author{
C. B. Panchal \\ Argonne National Laboratory \\ Argonne, Illinois 60439, U. S. A.
}

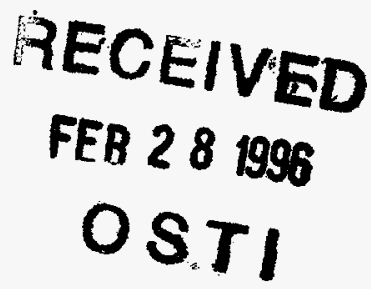

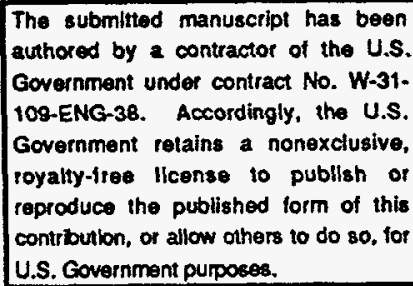

\section{DISCLAIMER}

\begin{abstract}
This report was prepared as an account of work sponsored by an agency of the United States Government. Neither the United States Government nor any agency thereof, nor any of their employees, makes any warranty, express or implied, or assumes any legal liability or responsibility for the accuracy, completeness, or usefulness of any information, apparatus, product, or process disclosed, or represents that its use would not infringe privately owned rights. Reference herein to any specific commercial product, process, or service by trade name, trademark, manufacturer, or otherwise does not necessarily constitute or imply its endorsement, recommendation, or favoring by the United States Government or any agency thereof. The views and opinions of authors expressed herein do not necessarily state or reflect those of the United States Government or any agency thereof.
\end{abstract}

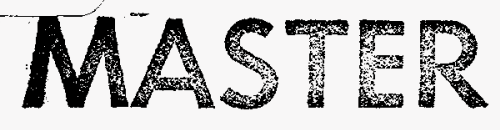




\section{DISCLAIMIER}

Portions of this document may be illegible in electronic image products. Images are produced from the best available original document. 


\title{
A GENERALIZED CORRELATION FOR CONDENSATION ON VERTICAL FLUTED SURFACES*
}

\author{
C.B. Panchal \\ Argonne National Laboratory \\ Argonne, Illinois 60439, U.S.A.
}

\begin{abstract}
A correlation was developed for laminar film condensation on vertical fluted surfaces. The theoretical analysis of Panchal and Bell was used for defining important physical property groups. The experimental data of Combs et al. were used to validate the proposed correlation. The experimental database used in the present study included four flute geometries that could be approximated to cosine type flutes and seven fluids. The resulting correlation can predict the average condensate heat-transfer coefficient within $\pm 20 \%$.
\end{abstract}

\section{INTRODUCTION}

Condensation of vapor on fluted surfaces has been recognized as an effective method for enhancing the heat transfer by utilizing the so-called "Gregorig Effect." Several experimental and theoretical analyses have been carried out to understand the basic mechanism. However, little work has been done for the development of a correlation that can be used for sizing fluted-tube condensers. Barnes and Rohsenow [1] rearranged the analytical results of Yamamoto and Ishibachi [2] and Panchal and Bell [3] to formulate a correlation for design applications. In earlier studies (e.g. [4], [5]), simplified approaches were taken for prediction of the condensate film coefficient and to optimize flute geometries for a given application.

The purpose of this study is to formulate a correlation based on the previous theoretical analysis [3] and validate it using the experimental data of Combs et al. [6] and Combs [7]. It should be noted that the basic flute shape e.g. cosine, triangular, parabolic, circular or square, has a significant effect on the performance. Therefore, it is difficult to develop a common correlation that can be used for all flute shapes. In the present study, a generalized correlation was formulated, and it was validated for cosine type flutes. With availability of experimental data, it should be possible to extend the application of this correlation to other flute shapes.

\footnotetext{
* This investigation was supported by the U.S. Department of Energy, Assistant Secretary for Energy Efficiency and Renewable Energy, Office of Industrial Technologies, under contract W-31-109-Eng-38.
} 


\section{FORMULATION OF CORRELATION}

The present analysis followed the previous work [3] and Nusselt's analysis of condensation on a plain vertical surface. In the previous work, the local Nusselt number at a given axial length was given as:

$\mathrm{Nu}=\mathrm{f}\left(\frac{\operatorname{Re}}{\operatorname{Re}_{\mathrm{f}}}, \frac{\mathrm{a}}{\mathrm{p}}\right)^{\mathrm{m}}$

The form assumed for the proposed correlation is:

$\mathrm{Nu}=\alpha \quad{\left.\operatorname{(Re} / \operatorname{Re}_{\mathrm{f}}\right)}^{\beta}{ }_{(\mathrm{a} / \mathrm{p})}^{\gamma} \phi^{\mathrm{m}}$

The physical property group, $\phi$ can be compared with that in Nusselt's analysis of condensation on a plain vertical surface. The term representing the gravity force for plain surfaces is replaced by a term that represents the surface tension force. Exponent, $m$, was $-0-.22$ in the theoretical analysis of Panchal and Bell [3]. It can be compared to the value of -0.25 in Nusselt's analysis. The flooding Reynolds number, $\operatorname{Re}_{\mathrm{f}}$, was defined as the film Reynolds number for flow conditions where flutes are completely filled with the condensate liquid. For the theoretical analysis, the condensation process was divided into two regions: thin film condensation in the crest region, and axial flow in the trough region. Figure 1 shows a schematic of the condensate film distribution on a fluted surface. The gravity force was assumed to be negligible in the crest region up to point $B$ in Figure 1. On the other hand, the surface tension force was assumed to be negligible in the trough region between points $\mathrm{B}$ and $\mathrm{C}$ in Figure 1. In real applications, the two fundamental forces acting on the condensate film would overlap, especially in the intermediate region. Therefore, Equation (2) needs to be rearranged for representation of both forces and necessary constants should be determined using the experimental data.

For plain surfaces, the following equation can be derived from Nusselt's analysis of laminar film condensation on a vertical plain surface:

$\overline{\mathrm{N}} \mathrm{u}=1.47 \mathrm{Re}^{-1 / 3}$ 
where the modified Nusselt number based on the average heat transfer coefficient is given by:

$\bar{N}_{\mathrm{u}}=\overline{\mathrm{h}}_{\mathrm{c}} /\left[\frac{\mathrm{k}_{l}{ }^{3} \rho_{l}\left(\rho_{l}-\rho_{\mathrm{v}}\right) \mathrm{g}}{\mu_{l}^{2}}\right]^{1 / 3}$

Following similar steps, an expression for the average Nusselt number for fluted surfaces was derived by integrating Equation (2) over the condenser tube length. The average heat-transfer coefficient, $\overline{\mathrm{h}}_{\mathrm{c}}$, is based on the total area of the fluted surface. The effect of $\mathrm{a} / \mathrm{p}$ has been shown to be small [3], and therefore, it was not considered in the present analysis. The resulting equation after rearranging appropriate terms was expressed in the following form:

$\overline{\mathrm{Nu}}=\alpha\left(\operatorname{Re} / \operatorname{Re}_{\mathrm{f}}\right)^{\beta} \Omega^{\mathrm{n}} \operatorname{Re}^{-1 / \beta} \mathrm{F}$

The function F represents the residual terms of the physical property groups raised to the power of $([n /(1-n)]-1 / 3)$. In general, the value for $n$ is close to 0.25 as reported in the previous work [3] (for $\mathrm{n}=0.25, \mathrm{~F}=1$ ). In the present analysis, $\mathrm{F}=1$ was assumed. It should be noted that $\Omega$ represents the ratio of the surface tension to gravity forces, and depending upon physical parameters, one of the two forces becomes dominant for the condensation process. For $a \rightarrow o$ or $\rho=\infty, \Omega \rightarrow o \operatorname{Re} \rightarrow \operatorname{Re}_{f}$; therefore, Equation (5) is identical to Equation (3). On the other hand, for $n=1 / 3$, the gravity force term is eliminated from Equation (5), and the condensation process is governed by the surface tension force only. For most cases, $n$ should be between zero and $1 / 3$, and it should be a function of basic flute shape factor, e.g. cosine, triangular, square, circular and parabolic flute surfaces.

\section{EXPERIMENTAL DATABASE}

Oak Ridge National Laboratory (ORNL) has conducted an extensive experimental program for condensation on vertical tubes [6], [7], and [8]. A total of eight fluted tubes and one plain tube were tested with seven fluids in various combinations. Out of eight fluted tubes, four had surfaces that could be closely approximated as cosine type flutes. Others had either large circular, square or sharp edge fluted surfaces. In the present analysis, the experimental data for the four cosine type fluted tubes were used. A summary of 321 experimental test runs used in the present analysis and flute specifications as reported in [6] are shown in Table 1. Flute pitch, p, was calculated by 
dividing the mean outside diameter by number of flutes. Flute amplitude, however, could not be accurately measured. Therefore, amplitude for each test section was backcalculated from the measured perimeter. For some test runs, the tube section was divided into 2,4 , or 8 sections by skirts around the tube perimeter. The skirts were intended to force the condensate off the tube surface, so that the condensation process could start anew, effectively reducing the tube length and increasing the average heat-transfer coefficient.

Table 1. Summary of Experimental Data

\begin{tabular}{|c|c|c|c|c|c|c|c|c|c|}
\hline \multicolumn{3}{|c|}{ Flute Geometry } & \multicolumn{6}{c|}{ Number of test runs } \\
\hline Amplitude & Pitch & Perimeter & \multicolumn{5}{c|}{ Test fluids } \\
\hline $\mathrm{mm}$ & $\mathrm{mm}$ & $\mathrm{mm}$ & $\mathrm{R}-11$ & $\mathrm{R}-22$ & $\mathrm{R}-113$ & $\mathrm{R}-114$ & $\mathrm{R}-115$ & $\begin{array}{c}\text { iso- } \\
\text { butane }\end{array}$ & $\begin{array}{c}\text { ammo- } \\
\text { nia }\end{array}$ \\
\hline 0.61 & 3.59 & 89 & 11 & & 12 & 13 & & & \\
\hline 0.26 & 2.22 & 89 & 20 & 16 & 16 & 17 & 20 & & \\
\hline 0.14 & 1.60 & 83 & 36 & & 48 & & 38 & 14 & 32 \\
\hline 0.41 & 3.65 & 97 & 8 & & & & 7 & & 13 \\
\hline
\end{tabular}

Condensation of vapor took place on the outside of tubes. The experimental tests covered the range of heat flux of 3 to $30 \mathrm{~kW} / \mathrm{m}^{2}$ and saturation condensing temperature of 30 to $50^{\circ} \mathrm{C}$. Each data point shown in Table 1 consists of one Wilson plot in which four water flow rates were used. The inlet water temperature was maintained constant during the Wilson plot tests; however, the saturation temperature at which condensation took place varied in the range of 1 to $4^{\circ} \mathrm{C}$. The average heat-transfer coefficient was calculated by subtracting the wall resistance from the Wilson plot intercept. The wall resistance was calculated assuming wall thickness equal to the difference of outside mean diameter and inside diameter. An exponent of 0.85 for the Reynolds number was used in the Wilson plot method. It was derived from Pethukov-Popov [9] correlation which is supposed to be the best correlation for water in the present range of operating conditions.

\section{RESULTS AND DISCUSSION}

The average heat-transfer coefficient determined from the Wilson plot was used to calculate the average Nusselt number as defined in Equation (4). The film Reynolds number Re, was calculated using the experimentally measured rate of condensation. The flooding Reynolds number, $\operatorname{Re}_{\mathrm{f}}$, was 
estimated using the following correlation derived using the analytical results for laminar flow [3].

$\lambda_{\mathrm{f}}=36(\mathrm{a} / \mathrm{p}) \exp (3.33 \mathrm{a} / \mathrm{p}) \mathrm{Re}_{\mathrm{f}}$

where

$\lambda_{\mathrm{f}}=4 \frac{\rho_{l}\left(\rho_{l}-\rho_{\mathrm{V}}\right)}{\mu_{l}^{2}} \mathrm{~g} \frac{(2 \mathrm{a})^{4}}{\mathrm{X}_{\mathrm{L}}}$

A regression analysis was used for determination of constants $\alpha, \beta$ and $n$ in Equation (5) by minimizing error, $\mathrm{E}$, calculated as follows:

$E=\Sigma \sqrt{\left(\bar{N} u_{e}-\bar{N} u_{c}\right)^{2}}$

The experimental Nusselt number $\overline{\mathrm{N}} \mathrm{u}_{e}$, was calculated using Equation (4), and the calculated Nusselt number, $\bar{N} u_{c}$, was determined using Equation (5) for a given set of constants $\alpha, \beta$ and $n$. Different initial values for constants were given to evaluate uniqueness of the solution. The resulting values were $\alpha=4.677, \beta=-0.014$, and $n=0.182$. Figure 2 shows the comparison of experimental and calculated Nusselt numbers. It is seen that out of 321 data points, only 25 lie outside the $20 \%$ boundary lines. It should be noted that the majority of those 25 points have film Reynolds numbers greater than flooding values. The correlation tends to predict higher heat transfer coefficient for such data points.

The experimental data are replotted in Figure 3, where the Nusselt number, $\bar{N} u$ is shown as a function of the film Reynolds number. It should be noted that for the ordinate system, the Nusselt number is divided by the term $\Omega^{0.182}$, so that the present analysis can be compared with plain surface correlations. The experimental data show that the laminar film condensation behavior (negative slope) continues much beyond film Reynolds numbers at which turbulent flow condensation is observed for plain vertical surfaces [10]. For fluted surfaces, condensate is drawn into the grooves of the flutes by surface tension forces. This produces a very thin film on the crest region as shown in Figure 1. Therefore, laminar flow for the crest region, where major condensation heat transfer takes place, prevails even though bulk flow in the grooves may be turbulent. Reduction in the heat-transfer coefficient as the film Reynolds number increases is, in general, due to filling up of grooves and corresponding reduction in the effective crest area. However, at high film Reynolds numbers, turbulent flow in the grooves should contribute to the 
condensation heat transfer. It will give higher heat-transfer coefficient than that predicted by the theoretical analysis [3], where negligible heat transfer is assumed for the trough region.

Figure 3 shows that the present correlation follows the experimental data for the whole range of test conditions, including test runs with skirts that reduced the effective tube length. For the present range of parameters, $\Omega$ varied over the range of 4 for R-11 to 80 for ammonia. The reduced Reynolds number, $\mathrm{Re} / \mathrm{Re}_{\mathrm{f}}$, varied over the range from 0.01 for test section with skirts to values greater than 1 for a limited number of runs that had flooded conditions. For comparison, the Nusselt equation for laminar film condensation and Colburn analysis for turbulent flow condensation on vertical plain surfaces are shown in Figure 3. The original analysis by Nusselt for plain vertical surfaces has been improved by incorporating the effects of the wavy interface, transition to turbulent flow at low film Reynolds numbers $(<2100)$ and vapor shear. The resulting effects of the film Reynolds number on the condensate heat-transfer coefficient for plain surfaces is smaller than that shown by the Nusselt equation. For fluted surfaces, however, the experimental results and correlation show that the film Reynolds number has a significant effect on the average heat-transfer coefficient. As a result, the heat transfer augmentation is reduced for high film Reynolds numbers, especially when flutes are flooded for a major part of the condenser tubes.

\section{CONCLUSION}

An analysis was carried out for the development of a correlation for condensation on vertical fluted surfaces. The correlation was derived from a theoretical analysis, and it was validated using the experimental database that included four flute geometries and seven fluids. A reasonably good agreement between calculated and experimental heat-transfer coefficients was achieved. Therefore, it can be concluded that on an average basis, condensation on fluted surfaces follows the general behavior predicted by theoretical analyses. 


\section{NOMENCLATURE}

a Amplitude of flute, $m$

g Gravitational acceleration, $\mathrm{m}^{2} / \mathrm{s}$

$h_{c} \quad$ Local heat-transfer coefficient based on total surface area, $k w / m^{2} K$

$\bar{h}_{c} \quad$ Average heat-transfer coefficient based on total surface area, $\mathrm{kW} / \mathrm{m}^{2} / \mathrm{K}$

$\mathrm{h}_{\mathrm{fg}} \quad$ Heat of condensation, $\mathrm{kJ} / \mathrm{kg}$

$\mathrm{k}$ Thermal conductivity, $\mathrm{kW} / \mathrm{m}$

L Tube length, $m$

$\mathrm{m}$ Constant in Equation (1)

n Constant in Equation (5)

$\mathrm{Nu} \quad$ Nusselt number, $\overline{\mathrm{h}}_{\mathrm{c}} \mathrm{p} / \mathrm{k}_{\mathrm{f}}$

$\overline{\mathrm{Nu}} \quad$ Average Nusselt number defined in Eq. (4)

$\mathrm{p} \quad$ Pitch of flute, $\mathrm{m}$

Re Film Reynolds number

$\operatorname{Re}_{\mathrm{f}} \quad$ Flooded Reynolds number

$\Delta \mathrm{T} \quad$ Temperature difference, $\mathrm{K}$

$X_{L} \quad$ Perimeter per half-flute, $m$

\section{Greek Letters}

$\alpha \quad$ Constant in Eq. (2)

$\beta \quad$ Constant in Eq. (2)

$\gamma \quad$ Constant in Eq. (2)

$\Omega \quad$ Dimensionless group, $\sigma a \mathrm{~L} / \mathrm{p}^{4} \mathrm{~g}\left(\rho_{l} \rho_{\vee}\right)$

$\sigma \quad$ Surface tension coefficient, $N / m$

$\lambda_{\mathrm{f}} \quad$ Dimensionless group defined in Eq. (7)

$\phi \quad$ Dimensionless group,

$$
\frac{\mathbf{k}_{l} \mu_{l} \Delta \mathrm{T}}{\rho_{l} h_{\mathrm{fg}} \sigma \mathrm{a}}
$$

$\rho$ Density, $\mathrm{kg} / \mathrm{m}^{3}$

$\mu \quad$ Viscosity, $\mathrm{kg} / \mathrm{ms}$

Subscript

$l \quad$ Liquid

$\checkmark \quad$ Vapor 


\section{REFERENCES}

1. Barnes, C.G., and Rohsenow, W.M., Vertical Fluted Tube Condenser Performance Prediction, Proc. 7th Int. Heat Transfer Conf., Munich, vol. 5, pp. 39-43, 1982.

2. Yamamoto, H., and Ishibachi, T., Calculation of Condensation Heat Transfer Coefficients of fluted Tubes, Heat Transfer Japanese Research, vol. 6, pp. 61-68, 1977.

3. Panchal, C.B., and Bell, K.J., Analysis of Nusselt-Type Condensation on a Vertical Fluted Surface, Numerical Heat Transfer, vol. 3, pp. 357-371, 1980.

4. Zener, C., and Lavi, A., Drainage Systems for Condensation, J. Eng. Power, vol. 96, pp. 209-215, 1974.

5. Webb, R.L., A. Generalized Procedure for the Design and Optimization of Fluted Gregorig Condensing Surfaces, Proc. 5th Annual Conf. Ocean Thermal Energy Conversion, Miami, vol. 3, pp. 123-145, 1978.

6. Combs, S.K., Mailen, G.S., and Murphy, R.W., Condensation of Refrigerants on Vertical Fluted Tubes, Oak Ridge National Laboratory Report, ORNL-5848, 1978.

7. Combs, S.K., An Experimental Study of Heat Transfer Enhancement for Ammonia Condensing on Vertical Fluted Tubes, Oak Ridge National Laboratory Report, ORNL5356, 1978.

8. Domingo, N., Condensation of Ammonia on the Outside of Smooth and Fluted Tubes at Various Tube Positions, Oak Ridge National Laboratory Report, ORNL-5826, 1982.

9. Pethukov, B.S., Heat Transfer and Friction in Turbulent Pipe Flow with Variable Physical Properties, Advances in Heat Transfer, vol. 6, pp. 503, 1970.

10. Blangetti, F.L., and Schlünder, E.U., Local Heat Transfer Coefficients in Film Condensation at High Prandtl Numbers, Condensation Heat Transfer, ASME Publication, New York, pp. 17-25, 1979. 
Figure 1. Shematic diagram of flute

Figure 2. Comparison of experimental and calculated Nusselt numbers

Figure 3. Condensation heat transfer coefficient as a function of film Reynolds number 


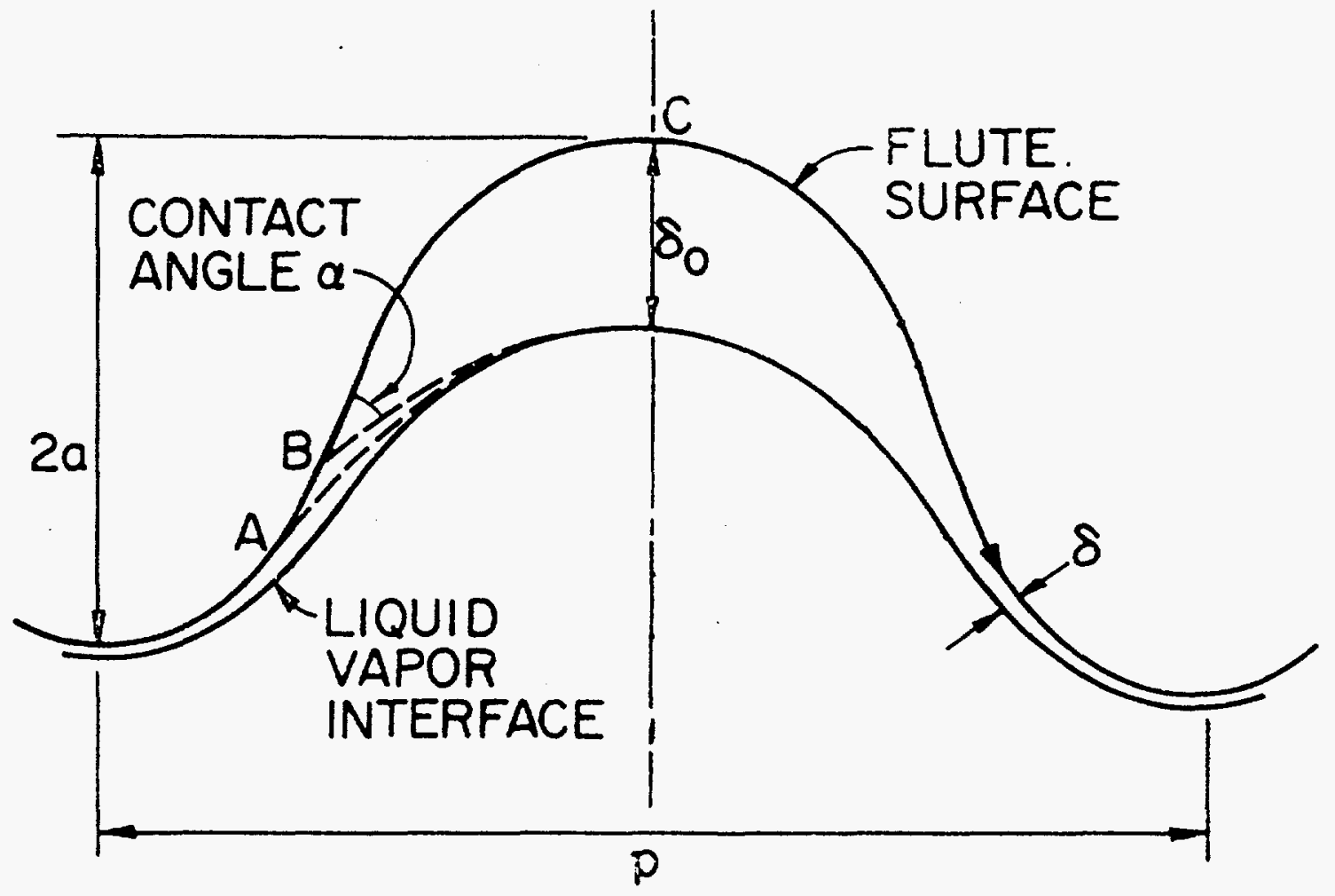




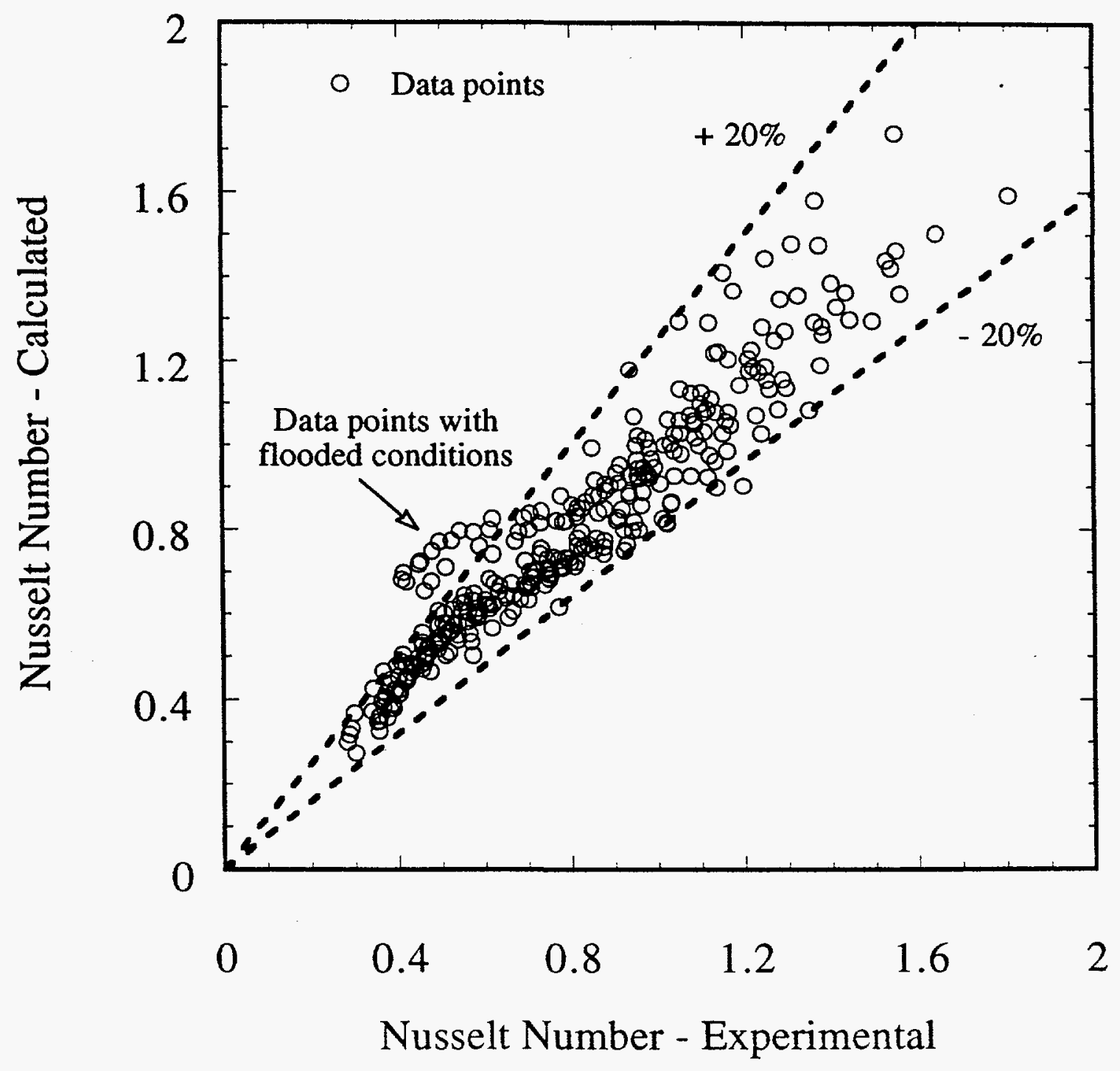




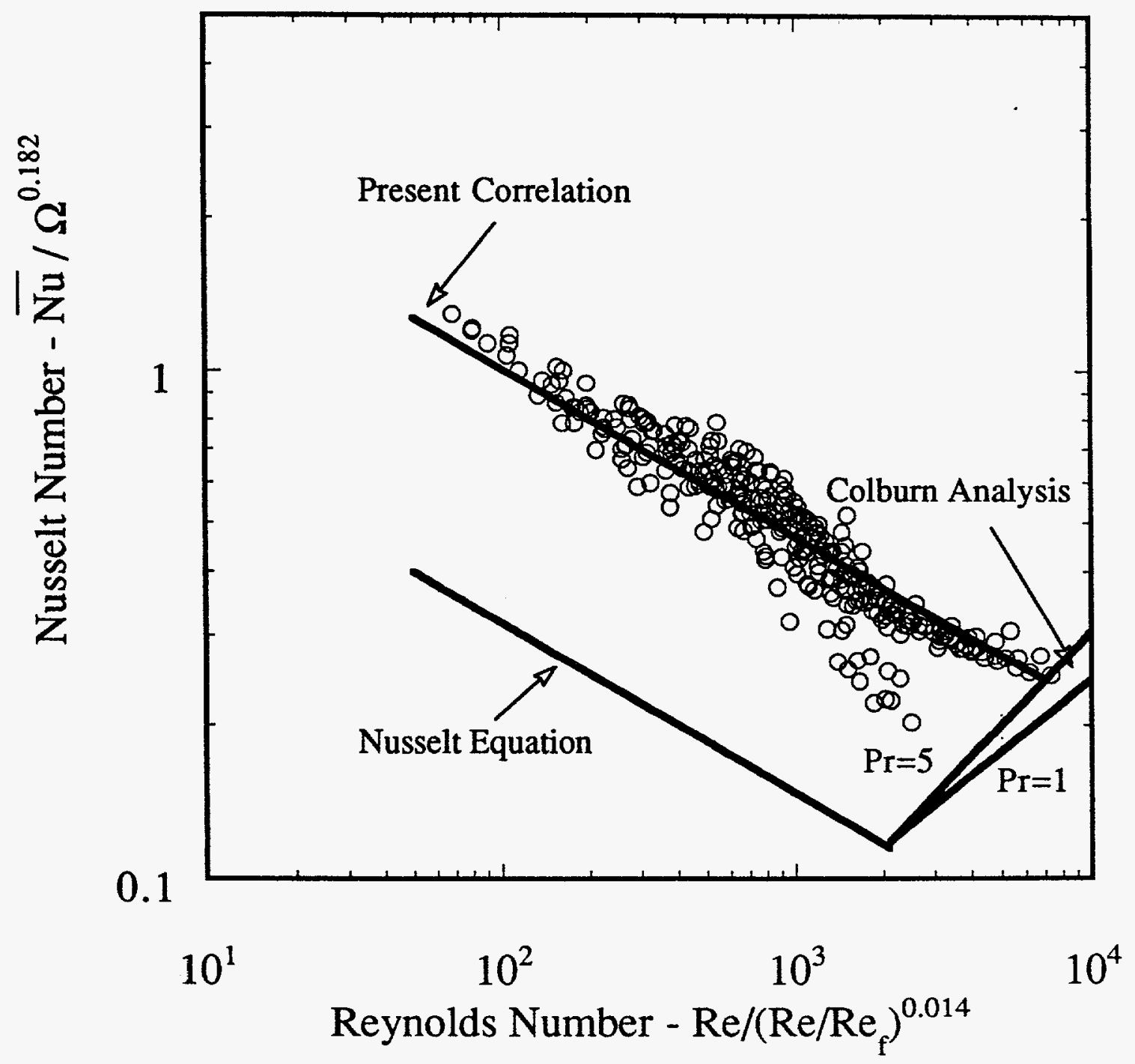

